\title{
AUTOMATIZAÇÃO DA CONTABILIDADE E O FUTURO DA PROFISSÃO CONTÁBIL
}

\section{ARTIGO ORIGINAL}

SUMAR, Ramiro Rodrigues ${ }^{1}$

SUMAR, Ramiro Rodrigues. Automatização Da Contabilidade E O Futuro Da Profissão Contábil. Revista Científica Multidisciplinar Núcleo do Conhecimento. Ano 06, Ed. 06, Vol. 17, pp. 167-181. Junho de 2021. ISSN: 2448-0959, Link de acesso: https://www.nucleodoconhecimento.com.br/contabilidade/profissao-contabil, DOI: 10.32749/nucleodoconhecimento.com.br/contabilidade/profissao-contabil

\section{RESUMO}

A presença de qualidade nos serviços prestados é de fato imprescindível para a sobrevivência da profissão contábil, uma vez que se traduz no objetivo de um contador. Os sistemas de informação, as novas tecnologias de inteligência artificial e a inovação, quando conectados com o conhecimento especializado dos profissionais da contabilidade, podem resultar em um maior desempenho das empresas e, consequentemente, da economia. Considerando que a profissão do contador busca fornecer informações tributárias ao fisco, o presente artigo tem como objetivo demonstrar que esta profissão está em um processo de migração no que diz respeito a automatização das tarefas, a fim de se tornar um instrumento de gestão capaz de auxiliar nas tomadas de decisões assertivas, de modo a contribuir para o desempenho da responsabilidade social das companhias. A problematização deste estudo se baseia na seguinte questão problema: Qual será o papel do contador com a automatização da contabilidade? A profissão contábil acabará conforme prevê o instituto Sapiens em pesquisa de 2018? Para o alcance dos objetivos utilizou-se da revisão bibliográfica. Como resultados, o artigo demonstrou o papel do contador no

\footnotetext{
${ }^{1}$ Mestrando em Controladoria, Especialista em Gestão de Tecnologia, Administração estratégica, Segurança da informação e Graduado em Ciências Contábeis.
}

RC: 90183

Disponível em: https://www.nucleodoconhecimento.com.br/contabilidade/profissao-contabil 
processo de desenvolvimento e crescimento das empresas antes e após a automatização dos processos burocráticos, assim como a perspectiva de cenário futuro da profissão. Sendo assim, verificou-se que a profissão contábil sofre uma mudança brusca de posicionamento para que sobreviva como profissão e mantenha o seu papel junto à sociedade e economia do país.

Palavras-Chaves: Automatização Contábil, Profissional contábil, Responsabilidade Social, Tomada de decisões.

\section{INTRODUÇÃO}

Vive-se um cenário de grandes mudanças no mercado contábil, com novas tecnologias, emprego de inteligência artificial e automatização de processos. E junto a estas mudanças têm-se as preocupações, as ansiedades e incertezas que o novo desperta nas pessoas (SOUZA et al., 2018).

Essas mudanças no país são vistas e sentidas por todos, onde a inflação não é mais considerada um problema, os índices de desemprego diminuíram, o acesso ao crédito e ao consumo aumentou e como consequência os índices de pobreza reduziram (CUNHA, 2019).

Portanto, observa-se um cenário empreendedor, em que novas companhias surgem a cada dia e mais profissionais são requisitados, mas algumas profissões correm o risco de inexistir devido à tecnologia e automatização (LEITE, 2017; ARAÚJO, 2020).

Conforme Rozenbaum (2018), um estudo realizado no ano de 2018 pelo instituto francês Sapiens revela que cinco profissões estão com risco de serem extintas, dentre elas se encontra o profissional de contabilidade que atua em escritório sem acesso à tecnologia como, por exemplo, o uso de computadores.

O contador moderno, ainda tem que lidar com a parte burocrática, as legalidades e grande quantidade de papéis que ocupam espaço. Visto que a automatização de processos e outros adventos para facilitar os trabalhos da contabilidade são provenientes das tecnologias, o profissional contábil terá que se adaptar ao uso da 
tecnologia ao seu favor, ou ser relutante a mudanças e ver sua profissão desaparecer ante a automatização (DINIZ, 2014).

Segundo o estudo do instituto francês, um número acima de dois milhões de pessoas "têm uma forte probabilidade de ver seus empregos desaparecem nos próximos anos". Os dados para o estudo foram do DARES (Serviço de Estudos Estatísticos do Ministério do Trabalho da França) e nele, por exemplo, pode-se observar que os trabalhadores de bancos podem desaparecer totalmente até 2050 e os contadores em 2056 (ROZENBAUM, 2018).

A competitividade exposta no mercado, com empresários buscando a cada dia inovação e novas tecnologias para ampliar o seu negócio, faz com que o profissional contábil esteja inserido neste meio. As empresas diante do mercado competitivo não podem deixar de ter ao lado a ajuda do contador, já que este profissional tem em sua atribuição almejar a qualidade e eficiência em todos os âmbitos do negócio (CHIAVENATO, 2004).

Outro ponto é que, a geração millennials está tomando conta do mercado de trabalho e ganhando posições na hierarquia das empresas e na tomada de decisões. Então para o profissional contábil é importante saber e entender este público que esperam agilidade e qualidade nos serviços de contabilidade.

Contudo, a finalidade deste artigo é estudar o futuro da profissão de contabilidade e a automatização que vem ocorrendo nos trabalhos contábeis. Estas mudanças são necessárias para manter o contador no mercado competitivo, bem como sua importância na geração de novos empregos, sua capacidade de empreender e inovar, quanto pela importância social ante a sua função contábil e fiscal.

A profissão contábil está passando por grandes transformações, deixando de ser o profissional que só traz problemas e contas, e atuando como apoio na gestão das empresas. Para tal, o profissional deve se enquadrar às novas exigências e inovar, a fim de manter seu papel e importância, não só para as empresas e gestores, mas, também, para a sociedade, posto seu papel social. 
A metodologia utilizada na escrita deste artigo foi a pesquisa bibliográfica, por meio de anais, pesquisas, livros, revistas, entrevistas da internet, matérias da internet e artigos acadêmicos publicados. Para Gil (2008), a pesquisa bibliográfica é desenvolvida tomando como base material já elaborado e constituído principalmente de monografias, dissertações, artigos científicos e livros.

Se tratando de finalidade, Marconi e Lakatos (1992) expõem que a pesquisa bibliográfica faz com que o observador tenha a oportunidade de entrar em contato diretamente com os materiais escritos sobre o assunto da pesquisa e auxiliar 0 pesquisador na sua análise ou no momento da manipulação das informações. A pesquisa bibliográfica é considerada como o primeiro passo para que seja iniciada uma pesquisa científica.

\section{REFERENCIAL TEÓRICO}

\subsection{HISTÓRICO DO PROFISSIONAL CONTÁBIL}

Existem relatos de que a figura do contador está presente desde o início da civilização. Segundo ludícibus e Marion (2006, p. 32): "[...] desde os povos mais primitivos, a Contabilidade já existia em função da necessidade de controlar, medir e preservar o patrimônio familiar e, até mesmo, em função de trocar bens para maior satisfação das pessoas $[\ldots] "$.

Apesar dos relatos, a existência oficial da contabilidade foi marcada na idade moderna, nos séculos XV a XVI, na região da Itália. No período de renascimento a profissão contábil ganhou espaço em áreas como: economia, artes, ciências e tecnologias (FIGUEIREDO; STRASSBURG, 2008).

No Brasil, antes mesmo de as primeiras escolas técnicas comerciais surgirem, a contabilidade era praticada pela figura do "guarda-livros", profissional definido segundo o Código Comercial de 1850 que, de acordo com Francisco D'Auria (1949), cuidava e registrar as transações dos estabelecimentos comerciais daquela época (CARVALHO, 2017). 
O desenvolvimento da profissão contábil sucedeu a aprovação do Decreto-lei no 9.295, de 27 de maio de 1946, que criou o Conselho Federal de Contabilidade e definiu as atribuições dos contadores, dos técnicos de contabilidade e dos guarda-livros (DOS SANTOS et al., 2019).

Com o conselho a profissão se expandiu e muitos problemas surgiram com a equiparação de profissionais com níveis de educação e conhecimento distintos. Se por um lado, existe o contador formado com um curso de graduação, coexistia, na mesma profissão, um profissional sem qualquer estudo (NETO, 2010).

Isso ocasionou o desinteresse dos jovens pela contabilidade, uma vez que o status dessa profissão não era o mesmo das outras formações como Direito e Economia. Como despertar o interesse em uma profissão que apresenta níveis de profissionais opostos um ao outro? Isso só foi possível com a prova de proficiência e a separação do técnico contábil para o Contador, propriamente dito.

Em 1972, ocorreu a regulamentação da auditoria, por meio da Resolução $n^{\circ} 220$, bem como das Circulares n ${ }^{\circ} 178$ e $n^{\circ} 179$ do Banco Central do Brasil. Nela foram impostos padrões demonstrativos que exigiram dos profissionais uma adaptação submetida a uma auditoria por pessoas certificadas (ABREU, 2013; CORDEIRO, 2011).

Contudo, a profissão contábil recebeu status somente em dezembro de 1976 com a promulgação da Lei 6.404 conhecida como lei das SA (Sociedades Anônimas). Esta lei originou a Comissão de Valores Mobiliários (CVM), que veio a substituir o Banco Central, a respeito da emissão de pareceres e parte da legislação da contabilidade, bem como do controle do mercado de capitais no Brasil (CARVALHOSA, 2017).

Para Santos (2008, p. 9)

[...] nos últimos anos, principalmente depois do fim da era de alta inflação, a partir da metade dos anos 1990, passou por um período de grandes mudanças e adaptações. As empresas que foram mais ágeis em ajustar seu foco para o seu negócio principal, seu core business, e não mais gerenciar os ganhos e as receitas inflacionárias, obteve maior índice de sucesso. E, nesse momento, o profissional contábil 
tem participação primordial ao prestar orientações tributária, societária e financeira. [...]. O contador, cada vez mais, é a bússola da empresa.

É observado que as exigências de competências e habilidades do profissional da contabilidade se mostram voltadas para estratégias e tomada de decisões nas empresas. Devido às mudanças tecnológicas, governos, empresas e gestores estão em um alto grau de inovação, exigindo cada vez mais do profissional contábil que, por sua vez, auxiliam as tomadas de decisões (DE OLIVEIRA REIS et al., 2015).

Em um ambiente altamente competitivo e ágil, obter informações de forma segura é um diferencial. A precisão e confiabilidade também são exigidas pelas empresas modernas que querem garantir sua sobrevivência no mercado e tornar a figura do contador um cientista de dados do patrimônio e dos lançamentos contábeis, exigindo que ele saiba interpretar os dados e traçar estratégias e caminhos que garantam melhores resultados. Todas estas exigências vêm de encontro com o que Santos (2008, p. 10) escreve em seu livro:

[...] o contador não deve perder da mente que a contabilidade não é para ele, é para o usuário. A contabilidade é a linguagem dos negócios e essa linguagem conta a história de cada empresa. Aperfeiçoar essa linguagem buscando aumentar seu poder de predição e de utilidade para o usuário é talvez a principal missão do contador. [...]

Portanto, o profissional deve estar em processo de aprendizagem, atualização e educação para que seja especialista em sua função e na obtenção de dados que auxiliem a corporação no seu objetivo social. O fácil acesso a cursos de pósgraduação na área de contabilidade traz ao indivíduo a oportunidade de estar posicionado junto ao mercado para contribuir com as empresas, a economia e com a sociedade.

\subsection{DESENVOLVIMENTO E CRESCIMENTO ECONÔMICO}

Furtado (1964) define o desenvolvimento econômico como "um processo de mudança social pelo qual um número crescente de necessidades humanas é satisfeito através de uma diferenciação no sistema produtivo decorrente da introdução de inovações tecnológicas". 
Já para Hewlett (1981), o desenvolvimento econômico é definido como "um aumento significativo na renda real per capita de uma nação, tem como propósito a obtenção de melhor alimentação, saúde, educação, melhores condições de vida e uma gama cada vez mais ampla de oportunidades de trabalho e de lazer para as pessoas desta nação".

Por outro lado, tem-se o crescimento econômico que, de acordo com Siedenberg (2006), consiste em um "processo de mudanças de caráter predominantemente quantitativo, significando aumento em dimensão, volume e/ou quantidade". Resumindo o que Vasconcellos (2000) concluiu, ao apontar que o crescimento econômico é o crescimento contínuo da renda per capita ao longo de um tempo.

O crescimento e a manutenção do Produto Interno Bruto (PIB) promovem maior qualidade de vida à população. Ademais, inovações tecnológicas, o aumento da receita nacional, a expansão da força de trabalho e a poupança são outros fatores que ajudam no crescimento econômico de um país.

Observa-se que quando um país apresenta um crescimento econômico o número de pessoas desempregadas diminui, ao passo que os impostos recolhidos aumentam. Nesse contexto, tem-se a necessidade de se investir mais para manter o crescimento contínuo da economia. Mendes (2015) expõe que a economia e o crescimento dos pais tiveram um baixo desempenho devido a alguns fatores, dentre eles a educação e a alta carga tributária.

Alinhado ao crescimento econômico vem o desenvolvimento econômico que para existir é necessário que o país mantenha indicadores e tenha fatores para a melhoria da qualidade de vida e renda da população ao longo do tempo. Para Rocha (2004) o que demonstra estes fatores é: o crescimento do bem-estar econômico, medido através dos indicadores de natureza econômica, entre os quais, é válido citar o produto nacional total e o produto nacional per capita; a redução dos níveis de pobreza, desemprego e social; e a elevação das condições de saúde, nutrição, educação e moradia. 
O Índice de Desenvolvimento Humano - IDH, da Organização das Nações Unidas (ONU), é uma unidade de medida criada e utilizada para se verificar o grau de desenvolvimento de um determinado país que abrange os quesitos de saúde, educação e renda. $O$ índice é uma referência numérica que tem sua variação definida entre 0 e 1 , nas suas definições quanto mais o valor estiver próximo a 1, melhor deve ser o desenvolvimento daquele local nos quesitos apresentados. Nenhum país tem IDH definido em zero e nem mesmo em um (FILGUEIRA et al., 2010).

Conforme o relatório da ONU que tem a avaliação de 189 países, o Brasil alcançou 0,761 pontos em 2018, o que representa um aumento significativo em comparação com 2013, onde recebeu 0,752 .

A posição do Brasil está em 79º no ranking, ao lado de Colômbia e enquadrado entre os países de categoria de alto desenvolvimento humano. No relatório o indicador mais alto é o da Noruega com 0,954 pontos, e listado com o pior índice de desenvolvimento humano está Níger com 0,377 (LEUSIN JÚNIOR, 2015).

\subsection{NOVAS TECNOLOGIAS NA CONTABILIDADE}

As novas tecnologias acabam gerando mudanças estruturais nas organizações com a sua aplicação, impactando nos custos das empresas e na modificação de seus processos produtivos, tendo em vista a competitividade no mercado (MAT, 2010).

Scott (2009) enfatiza que o uso da tecnologia na contabilidade é uma mudança sem precedente, isto é, não é fácil identificar se os seus impactos foram negativos ou positivos. Por outro ponto de vista, Alsharayri (2011) e Choe (2004) mostram que o nível de tecnologia e as informações produzidas têm impactos positivos.

A tecnologia causa impactos positivos tanto na agilidade e confiabilidade quanto na segurança dos sistemas de informações utilizados nas empresas por escritórios de contabilidade e pelos profissionais. A função das informações geradas pelos sistemas, segundo Allahyari e Ramazani (2011), é auxiliar seus usuários a tomarem decisões, tendo em vista que a contabilidade tem condições de produzir informações relevantes 
para a formulação de negócios e processos estratégicos, para o controle das atividades e para o crescimento das empresas.

Para Scott (2009), a vantagem da tecnologia está no uso de diversas ferramentas para agilizar a execução de funções exercidas pelo contador. Nesse aspecto, a tecnologia contribui para avanço operacional da contabilidade frente à competitividade, posto a velocidade e a eficiência oferecidas pelos avanços tecnológicos.

Acevedo (2012) mostra que se as comunicações em empresas contábeis forem rápidas podem ajudar a aumentar a produtividade, bem como podem melhorar a tomada de decisão e facilitar o crescimento das empresas.

Ainda segundo Scott (2009), uma desvantagem da tecnologia é a sua dependência de seres humanos. A tecnologia surge de inovação humana, portanto, é um produto que repete os mesmos erros humanos. Mas isso pode ser contornado com processos mais robustos e com uma especialização e educação mais focada na automatização. Ele também demonstra que outra desvantagem é a dependência da profissão pela tecnologia, mas já sabe-se que estudos mostram que o contador que existia para operacionalizar cálculos irá se extinguir, o que vem de encontro com este pensamento errôneo do autor.

Aribaba et al. (2011), por sua vez, destacam a importância que a tecnologia agrega para a sociedade, principalmente, nas pequenas empresas de prestação de serviços, visto a melhora do desempenho e o maior desenvolvimento empresarial. Sendo assim, com mais desempenho surgem mais oportunidade e ganhos, com isso empregos são gerados e a economia é beneficiada.

A competitividade exige que as organizações contábeis sejam capazes de criar valor para os seus clientes. Clientes estes que são pagadores de impostos e contratantes de pessoal. Segundo Simons (1987), ao se diferenciarem dos seus concorrentes, implantando e formulando uma estratégia empresarial bem definida, essas organizações irão agregar mais resultados. $\mathrm{Na}$ estratégia o uso de tecnologias 
agregado a sistemas contábeis é imprescindível, uma vez que fornece informações seguras e úteis (JERMIAS; GANI; 2004).

Ter uma estratégia bem definida e consolidada, com base em investimentos em tecnologia e em qualificação de pessoas, segundo Grande et al. (2011), trará vantagens produtivas e mudanças favoráveis para seus clientes ante a seus concorrentes.

\subsection{PAPEL DO CONTADOR NA INOVAÇÃO E AUTOMATIZAÇÃO DE PROCESSOS CONTÁBEIS}

Os números de escritórios de contabilidade aumentam e contribuem para a diminuição do desemprego, entre os anos de 2009 até 2012, de acordo com Gondim (2014). Foi registrado um aumento em mais de $60 \%$ de empregos formais e $5 \%$ de novas empresas de contabilidade.

O Conselho Federal de Contabilidade (CFC, 2014), expõe, em seu portal, uma pesquisa realizada que demonstra que mais de $58 \%$ dos profissionais da classe contábil têm a preferência de atuar em empresas da iniciativa privada ou abrir o próprio escritório a ter que prestar concurso e ingressar no setor público. Veja que estes dados mostram a contribuição para a geração dos números de empregos formal e informal, uma vez que o profissional contábil atua junto aos gestores das empresas (seus clientes) colaborando para que o negócio evolua e cresça e necessite de mais empregados.

Ajudando aos empreendedores ou investindo em seu próprio negócio, se utilizando de conhecimentos práticos e teóricos adquiridos, o contador tem um papel significante na economia. Nos últimos anos a contabilidade deixou de apenas utilizar uma calculadora e resmas de papel (NOGUEIRA, 2010).

Veja que Coelho (2015) explica que o contador deixou de ser a pessoa que registra fatos passados para ser um consultor estratégico com uma visão prospectiva e ampla do mercado. Com base nestas mudanças o contator tem a missão de automatizar 
processos, gerar mais desempenho e compor os dados estatísticos de forma a apoiar as empresas e gestores na tomada de decisões.

Fávero et al. (2006) mostram que a "contabilidade tem como objetivo gerar informações para os diversos usuários para que possam tomar decisões". Esse objetivo parece simples, mas os fatores subjetivos envolvidos nele tornam este processo difícil, a dificuldade de compreensão dos dados e o distanciamento do contador do gestor torna tal objetivo difícil de ser cumprido. Vejamos que existem variáveis para a boa comunicação, e estas devem ser estudadas e de especialidade do contador, para que seu objetivo, enquanto profissional contábil, seja alcançado.

Como público-alvo das informações da contabilidade identifica-se a nova geração que precisa de informações confiáveis e exige que seja de forma rápida, vindo de encontro com Drucker (1987), o trabalho específico do gestor empreendedor de uma empresa é fazer com que os negócios desta empresa se tornem mais ágil e de qualidade.

Segundo dados disponíveis no site do CFC (2014), atualmente o Brasil conta com mais de 71.008 organizações/empresas contábeis e 515.011 profissionais registrados no Conselho Federal de Contabilidade e estes profissionais e escritórios devem estar preparados para a automatização dos processos.

Tendo o contador a função de orientar os gestores para o crescimento de suas empresas, este profissional também desempenha um importante papel na sociedade, e para tanto, deve sempre está em busca de atualizar seus conhecimentos e de se comportar eticamente, sendo o interlocutor do governo, com o contribuinte e a sociedade (CORONADO, 2017).

O contador que orienta seus clientes a contribuírem de forma correta, ajuda no desenvolvimento do estado e com isso no desenvolvimento do país. Neste papel, a automatização é a peça fundamental para que toda a atenção do contabilista esteja na geração de informações e não em tarefas chatas e morosas de conferências e lançamentos. 
Competência, profissionalismo, agilidade e especialização dos envolvidos nos processos fazem com que estes sejam mais coerentes, ágeis e funcionem de forma correta. A prática contábil eficiente e especializada é o ponto que se deve ter atenção para que os negócios se perpetuem e sejam cada vez mais eficientes e competitivos.

O profissional que entender estas mudanças comportamentais que vem acontecendo, se especializar e se atualizar, terão um papel importante e decisivo na sociedade e nas corporações. Todo o processo depende de um ser humano, e este, ser humano tem que ter as habilidades e competências para que o processo automatizado funcione corretamente, além de um conhecimento sistêmico das empresas. A especialização e o conhecimento aprofundado são ferramentas para este novo paradigma de mudança da profissão contábil.

\section{CONCLUSÃO}

Como exposto neste artigo, a profissão contábil desde o princípio é importante para o desenvolvimento e crescimento do País. A automatização dos processos contábeis e a mudança de exigências da profissão farão com que o profissional que hoje é visto como apenas o cumpridor de exigências legais seja extinto. Surge então a oportunidade para que a profissão e os profissionais se destaquem em outras áreas de seu conhecimento como a consultoria e a estratégia empresarial, posto o vasto conhecimento adquirido na educação para a formação.

Os escritórios de contabilidade contribuem com a geração de empregos, cumprindo assim com seu papel social, mas devem se adequar às novas dinâmicas dos sistemas de informação para que sejam eficientes e produzam com qualidade e agilidade as informações necessárias para as companhias e governos. Uma vez que a educação é alicerce para o desenvolvimento de qualquer nação, a melhoria da profissão e da educação do profissional acarreta uma melhora significativa na base da sociedade e com isso acontecimentos de melhoria social e profissional.

O profissional contábil tem deixado de ser aquele que só traz notícias ruins para as empresas, com guias e contas a pagar, fornecendo uma orientação estratégica aos 
empreendedores e gestores, contribuindo para que estes executem suas funções de maneira correta e com a agilidade que o mercado requer através de dados corretos e extraídos de forma rápida.

O Contador possui todas as ferramentas e conhecimentos para automatizar a preparação das demonstrações contábeis e lançamentos, de modo a trazer mais agilidade e confiabilidade, com isso surge como um aliado para as empresas desempenharem seu papel social com o crescimento empresarial.

As empresas crescendo de forma sólida, inteligente e cumprindo suas obrigações fiscais e societárias com qualidade e agilidade, papel este que o contador pode desempenhar junto a gestão, fará com que toda a sociedade se desenvolva. Se todos estiverem cumprindo o seu papel junto a economia e sociedade, novos empregos serão gerados, mais impostos serão pagos, os índices de pobreza diminuirão e a oferta educacional será maior.

A ameaça de inexistência da profissão fará com que os profissionais se reinventem e revejam a sua posição perante as inovações. Aqueles que tiverem uma visão diferente de sua posição como profissional contábil, se aliando às novas tecnologias de inteligência artificial, automatização e especialização ganharam espaço no mercado, diferente do profissional que ficar alheio às mudanças e lutar contra elas.

Por outro lado, o ensino da contabilidade precisa ser melhorado, para que as novas tecnologias sejam empregadas no ensino e para que os formandos saiam das universidades preparadas para encarar o mundo atual que exige agilidade e a qualidade na prestação dos serviços.

Observa-se uma lacuna a ser estudada quanto a distribuição demográfica dos profissionais da contabilidade visto o grau de inovação das empresas de determinadas regiões. Isto dará uma visão mais ampla do que pode ocorrer ou não com a carreira. Sugere-se também a realização de estudos de caso em empresas inovadoras com alto grau de automatização e o posicionamento do profissional perante esta 
companhia e seus resultados. Estes estudos contribuirão para um entendimento mais amplo do que poderá ocorrer no futuro.

\section{REFERÊNCIAS}

ABREU, E. N. de. Regulamentação de auditoria: estudo da influência das fraudes contábeis de 2001. Goiânia: Universidade Federal de Goiás - UFG, 2013.

ACEVEDO, L. Business benefits of information technology. Chron, 2019. Disponível em: <http://smallbusiness.chron.com/business-benefits-informationtechnology-4021.html>. Acesso em: 10/mai/2021

ALLAHYARI, A.; RAMAZANI, M. Firm technological change and its effects on management accounting change: case study of Iranian manufacturing firms. Global Journal of Management and Business Research, v. 11, n. 9, 2011.

ALSHARAYRI, M. A. The E-Commerce impact on improving accounting information system in Jordanian Hotels. International Research Journal of Finance and Economics, v. 75, 2011.

ARAÚJO, F. M. de. A inteligência artificial e os seus impactos no mundo do trabalho. Fortaleza: Centro Universitário Fametro, 2020.

ARIBABA, F. et al. An evaluation of the impact of technological innovative entrepreneurial development programmes on the performance of small scale business in Nigeria. Global Journal of Business, Management And Accounting, v. 1, n. 1, 2011.

CARVALHOSA, M. de S. B. Comentários à lei de sociedades anônimas. Saraiva Educação SA, Editora: Saraiva Educação S. A., v. 1. 2017.

CFC. Conselho Federal de Contabilidade. Dados estatísticos do Conselho Federal de Contabilidade. 2014. Disponível em: http://www.cfc.org.br/. Acesso em: 12/mai/2021. 
CHIAVENATO, I. Empreendedorismo: dando asas ao espírito empreendedor. Editora manole, $4^{\mathrm{a}}$ ed. 2004.

CHOE, J. Impact of management accounting information and AMT on organizational performance. Journal of Information Technology, v. 19, 2004.

COELHO, J. M. A. Contabilidade: uma carreira em transformação. Disponível em: http://www.portalcfc.org.br/noticia.php?new=23196. Acesso em: 12/mai/2021.

CORDEIRO, C. M. R. Auditoria e Governança corporativa. Editora: IESDE, 2011.

CORONADO, O. Contabilidade gerencial básica. Editora: Saraiva Educação SA, 2017.

CUNHA, E. S. Oferta de crédito e emprego local nos municípios da região Nordeste: 2002-2015. Salvador: Federal da Bahia. 2019.

D'AURIA, F. Primeiros princípios de contabilidade pura. São Paulo: Departamento de Cultura e Ação Social, 1949.

DE OLIVEIRA REIS, A. et al. Perfil do profissional contábil: habilidades, competências e imagem simbólica. Revista Contemporânea de contabilidade, v. 12, n. 25, p. 95-116, 2015.

DINIZ, E. R. da S. et al. Governança eletrônica no Brasil e o papel das tecnologias da informação e comunicação. Florianópolis: Universidade Federal de Santa Catarina, 2014.

DOS SANTOS, M. J. A. et al. Um estudo comparativo entre o exame de suficiência do conselho federal de contabilidade, o exame nacional de desempenho de estudantes e a pós-graduação stricto sensu dos cursos de ciências contábeis do Estado do Rio de Janeiro. Polêm!ca, v. 13, n. 4, p. 1681-1698, 2014.

DRUCKER, P. F. Inovação e Espírito Empreendedor: prática e princípios. São Paulo: Pioneira, 1987. 
FAVERO, H. L. et al. Teoria e Prática. 4 ed. Editora: Atlas, São Paulo. 2006.

FIGUEIREDO, C. R.; STRASSBURG, U. A Contabilidade: aspectos históricos que influenciaram no seu desenvolvimento no decorrer do tempo. IX Jornada de Estudos Contábeis-UNIOESTE, 2008.

FILGUEIRA, J. M. et al. Um panorama estatístico de cunho econômico, social e educacional do estado do Rio Grande do Norte. HOLOS, v. 4, p. 198-215, 2010.

FURTADO, C. Dialética do Desenvolvimento. Rio de Janeiro, $2^{a}$ ed., Fundo de Cultura, 1964.

GIL, A. C. Métodos e técnicas de pesquisa social. 6. ed. São Paulo: Atlas, 2008.

GONDIM, A. MEI também tem obrigações fiscais. Contábeis, 2016. Disponível em: https://www.contabeis.com.br/noticias/26714/mei-tambem-tem-obrigacoes-fiscais/.

GRANDE, E. U. et al. The impact of accounting information systems (AIS) on performance measures: empirical evidence in Spanish SMEs. The International Journal of Digital Accounting Research, v. 11, 2011.

HEWLETT, S. A. Dilemas do desenvolvimento. Rio de Janeiro: Zahar, 1981.

IUDÍCIBUS, S. de; MARION, J. C. Introdução à teoria da contabilidade para o nível de graduação. 4 ed. São Paulo. Editora: Atlas, 2006.

JERMIAS, J.; GANI, L. Integrating business strategy, organizational configurations and management accounting systems with business unit effectiveness: a fitness landscape approach. Management Accounting Research, v. $15,2004$.

LEITE, E. F. O fenômeno do empreendedorismo. Saraiva Educação SA, 2017.

LEUSIN JÚNIOR, S. A inserção internacional de potências médias: evidências da afirmação de países em desenvolvimento a luz da evolução do sistema 
multilateral de comércio. Porto Alegre: Universidade Federal do Rio Grande do Sul, 2015.

MARCONI, M. de A.; LAKATOS, E. M. Metodologia do trabalho científico. São Paulo: Editora Atlas, 1992. 4a ed.

MAT, T. Z. Management accounting and organizational change: impact of alignment of management accounting system, structure and strategy on performance. Philosophy School of Accounting, Finance and Economics Faculty of Business and Law Edith Cowan University. Perth Western Austrália, 2010.

MENDES, M. Por que a economia do Brasil foi para o buraco? Brasil economia e governo, 2015. Disponível em: http://www.brasil-economiagoverno.org.br/2015/08/25/por-que-a-economia-brasileira-foi-para-o-buraco/. Acesso em: 14/mai/2021.

NETO, O. R. M. A profissionalização do contador no Brasil. São Paulo: Mackpesquisa, $2010 . \quad$ Disponível em: http://168.197.92.160/bitstream/handle/10899/14605/721_2008_0_15.pdf?sequence $=1$ \&isAllowed $=\mathrm{y} /$. Acesso em: 14/mai/2021.

NOGUEIRA, M. Práticas de contabilidade: relatório de estágio do Mestrado em Gestão. Coimbra: [s.n], 2010.

RAMALHO, T. C. L. Contabilidade criativa: a percepção dos Técnicos Oficiais de Contas. Lisboa: Instituto Superior de Contabilidade e Administração de Lisboa. 2015.

ROCHA, F. J. M. Educação e economia: uma abordagem sobre as consequências e condicionantes econômicas do desenvolvimento humano, com ênfase em educação. Brasília: Cadastro de Finanças Públicas, n. 5, 2004.

ROZENBAUM, S. Revolução digital deixa cinco profissões à beira da extinção. rfi, 2018. Disponível em: https://www.rfi.fr/br/economia/20180829-revolucao-digitaldeixa-cinco-profissoes-beira-da-extincao-diz-estudo. 
SANTOS, R. F. dos. Introdução à contabilidade: noções fundamentais. São Paulo: Saraiva, 2008.

SCOTT, W. The impact technology is having on the accounting profession. World conference on higher education, 2009.

SIEDENBERG, D. R. Dicionário do Desenvolvimento Regional. Santa Cruz: Edunisc, 2006.

SIMONS, R. Accounting control systems and business strategy: an empirical analysis. Accounting, Organizations and Society, v. 12,1987.

SOUZA, E. C. et al. As características qualitativas da informação contábil a partir da percepção dos profissionais de contabilidade. In: Congresso UFPE de Ciências Contábeis. 2018.

VASCONCELLOS, M. A. S. de. Economia Micro e Macro: Teoria e Exercícios, Glossário com 260 Principais Conceitos Econômicos. São Paulo: Atlas, 2000.

Enviado: Agosto, 2020.

Aprovado: Junho, 2021. 